REVIEW

\title{
Iron, anaemia, and inflammatory bowel diseases
}

\author{
C Gasche, M C E Lomer, I Cavill, G Weiss
}

Gut 2004;53:1190-1197. doi: 10.1136/gut.2003.035758

Iron deficiency anaemia is one of the most common disorders in the world. Also, one third of inflammatory bowel disease (IBD) patients suffer from recurrent anaemia. Anaemia has significant impact on the quality of life of affected patients. Chronic fatigue, a frequent IBD symptom itself, is commonly caused by anaemia and may debilitate patients as much as abdominal pain or diarrhoea.

Common therapeutic targets are the mechanisms behind anaemia of chronic disease and iron deficiency. It is our experience that virtually all patients with IBD associated anaemia can be successfully treated with a combination of iron sucrose and erythropoietin, which then may positively affect the misled immune response in IBD.

See end of article for authors' affiliations

Correspondence to

Correspondence to:
Dr C Gasche, Allgemeines Krankenhaus Wien, Innere Medizin 4, Wahringer Gurtel 18, Vienna, A1090, Austria; christoph.gasche@ meduniwien.ac.at

Accepted for publication 4 February 2004

\section{SUMMARY}

Iron deficiency anaemia is one of the most common disorders in the world. The World Health Organization estimates that more than $30 \%$ of the population have iron deficiency anaemia yet it remains an under managed feature of many gastroenterological conditions. Also, one third of inflammatory bowel disease (IBD) patients suffer from recurrent anaemia. Anaemia has significant impact on the quality of life of affected patients. Chronic fatigue, a frequent IBD symptom itself, is commonly caused by anaemia and may debilitate patients as much as abdominal pain or diarrhoea. Both iron deficiency and anaemia of chronic disease contribute most to the development of anaemia in IBD. Cobalamin or folate deficiency and various other causes of anaemia such as haemolysis occur infrequently. Common therapeutic targets are the mechanisms behind anaemia of chronic disease and iron deficiency. Oral iron treatment is limited by poor absorption, intolerance, and induction of oxidative stress at the site of bowel inflammation. Intravenous iron sucrose has a good safety profile and a $65-75 \%$ response rate within $4-8$ weeks, which is paralleled by improvement in the quality of life. Combination therapy with erythropoietin (Epo) leads to a faster and larger haemoglobin increase. It is our experience that virtually all patients with IBD associated anaemia can be successfully treated with a combination of iron sucrose and Epo, which then may positively affect the misled immune response in IBD.

\section{IRON LOSS IN INFLAMMATORY BOWEL DISEASE}

Iron deficiency anaemia (IDA) can be considered a gastroenterological condition. The leading causes of iron deficiency (ID) in the developed world are menstruation and blood loss associated with gastrointestinal disease. In the latter case, blood loss in the stomach or intestine cannot be matched by duodenal iron absorption, creating a negative iron balance. This imbalance is often seen in IBD, leading to anaemia. While our understanding of IBD has grown over the past decades, the prevalence of IBD associated anaemia has changed only little: one third of IBD patients still have haemoglobin levels below $12 \mathrm{~g} / \mathrm{dl}{ }^{2}$

\section{"Anaemia is a consistent clinical feature of $\mathrm{IBD}^{\prime \prime}$}

Anaemia has been recognised as a key symptom of IBD. For a long time, the only laboratory parameter included in disease activity scores (such as the Crohn's disease activity index) was the haematocrit/haemoglobin ratio. Intestinal bleeding (either visible or occult blood) is a major symptom of the disease itself, and red blood cells (RBCs) may be lost with each flare. Indeed, anaemia is probably too common to be specifically recognised as a complication of IBD - anaemia is a consistent clinical feature of IBD. For patients, this can be the most debilitating aspect of their disease. Although efficient therapeutic options have been developed for the treatment of IBD associated anaemia, treating anaemia often has a low priority for gastroenterologists. Compared with other manifestations of the disease, such as arthritis or osteopathy, anaemia in IBD has been given scant attention. The purpose of this review is to transfer the current knowledge on IBD associated anaemia into the daily management of IBD.

\section{ANAEMIA}

RBCs circulate throughout the body engaged in gaseous exchange, oxygen transport, and carbon dioxide removal. Erythropoiesis must maintain steady state levels of circulating RBCs and respond to acute challenges. The bone marrow is a highly dynamic organ that produces two to three million red cells every second. These red cells are filled with haemoglobin and are replaced after 75-150 days. This process is controlled by the hypoxia sensing mechanism

Abbreviations: IBD, inflammatory bowel disease; ID, iron deficiency; IDA, iron deficiency anaemia; TPMT, thiopurine methyltransferase; $M C V$, mean cell volume; Epo, erythropoietin; $A C D$, anaemia of chronic disease; RBC, red blood cell; NRAMP-1, natural resistance associated macrophage protein; IFN- $\gamma$, interferon $\gamma$; TNF- $\alpha$, tumour necrosis factor $\alpha$; NO, nitric oxide; RES, reticuloendothelial system 
of the kidney which responds by modulating the output of Epo, which in turn determines the level of erythropoietic activity. When red cell production fails to match red cell destruction, the result is anaemia.

\section{Clinical consequence}

For a long time it was thought that the clinical symptoms of anaemia (such as fatigue, headache, dizziness, shortness of breath, or tachycardia) occurred only when the haemoglobin level dropped abruptly. It had been argued that patients would adapt to low haemoglobin levels if anaemia developed slowly. This has led to the concept of asymptomatic anaemia. In truth, asymptomatic reflects the fact that impairments in physical condition, quality of life, and cognitive function may be unrecognised by both patients and their doctors. This is a non-IBD specific dilemma. Nephrologists have learned this lesson in the recent past. ${ }^{3}$ They showed that the process of adaptation to chronic anaemia was in fact adaptation to lower quality of life and that this could be reversed.

Key symptoms such as dyspnoea and tachycardia are due to a decrease in blood oxygen levels and peripheral hypoxia. Compensatory blood shifting from the mesenteric arteries may worsen perfusion of the intestinal mucosa. ${ }^{4}$ Motility disorder, nausea, anorexia, and even malabsorption have been attributed to anaemia. Reduced metabolic and energy efficiency during physical activity also contribute to weight loss in anaemia. ${ }^{5}$ A common finding is menorrhagia and amenorrhoea among women. Men may suffer from impotence. Loss of libido may contribute to impaired quality of life in both sexes. ${ }^{6}$ Central hypoxia may lead to symptoms such as headache, dizziness, vertigo, or tinnitus. Several studies have confirmed that treatment of anaemia improves cognitive function. ${ }^{7}$ As iron is not only a component of haemoglobin and myoglobin but also of cytochromes and many other enzymes, ID alone may impair cognitive function. Indeed, correction of ID in non-anaemic girls improves verbal learning and memory. ${ }^{8}$

\section{Chronic fatigue}

Anaemia reduces the ability to perform normal daily activities. Chronic fatigue is a common symptom in IBD with anaemia, ID being one of the primary causative factors. ${ }^{9}$ Fatigue is associated with significant physical, emotional, psychological, and social consequences, with virtually every aspect of daily life being affected. On successful treatment of anaemia with Epo, most studies observed an improvement in energy and activity level and overall quality of life. ${ }^{10}$ Surprisingly, over the range $8-14 \mathrm{~g} / \mathrm{dl}$, the largest improvement in quality of life occurred when haemoglobin levels increased from 11 to $13 \mathrm{~g} / \mathrm{dl} .{ }^{11}$

\section{"Concern regarding the fatigue of IBD patients is probably as important as concern for their abdominal pain or diarrhoea" $^{\prime \prime}$}

Changes in quality of life were also studied in anaemic Crohn's disease patients treated with iron sucrose and Epo. ${ }^{12}$ The feeling of well being, mood, physical ability, and social activities accounted for most of the improvement in quality of life. Also, individual patients reported relief of disturbed sleep and increased appetite or libido. Using the same questionnaire, quality of life data were compared with data that had been assessed in anaemic patients. ${ }^{13}$ It is remarkable that the absolute quality of life in Crohn's disease associated anaemia matched well with data collected in patients with advanced cancer. $^{2}$

Oncologists have documented a significant communication gap between patients and physicians regarding fatigue. ${ }^{14}$ Concern regarding the fatigue of IBD patients is probably as important as concern for their abdominal pain or diarrhoea.

\section{AETIOLOGY OF ANAEMIA IN IBD}

The anaemia in IBD is complex and commonly represents a particular example of the combination of IDA and anaemia of chronic diseases (ACD).

\section{Iron deficiency}

In normal subjects, daily iron loss amounts to $1-2 \mathrm{mg}$ and this requires a similar amount to be taken up from the diet. Dietary iron occurs in two forms: haeme (from myoglobin meat, poultry, and fish) and non-haeme (mostly from plants). ${ }^{15}$ The molecular pathway of iron absorption has recently been reviewed. ${ }^{16}$ Non-haeme iron absorption depends on many factors, including the presence of gastric acid, ascorbic acid, and inhibitors such as phytic acid and polyphenols (in vegetables). Haeme iron is released after mechanical and enzymatic digestion of myoglobin. Food aversions and self reported intolerance are common in $\mathrm{IBD}^{1718}$ and this will affect the amount of iron available in the diet (table 1). Various reports have pointed to diminished iron intake in IBD (specifically in women) predominantly due to avoidance of high fibre fortified breakfast cereals which may be perceived to exacerbate abdominal symptoms. ${ }^{19}$ Changing dietary advice may not be easy, especially if it is viewed as exacerbating abdominal symptoms. Low dose iron supplementation is likely to be preferred.

The only way to lose iron is by menstrual and intestinal bleeding. Chronic intestinal bleeding in IBD may exceed the amount of iron that can be absorbed from the diet, resulting in a negative iron balance. ${ }^{20}$ Although iron absorption in IBD is not generally abnormal, it can be occasionally impaired in Crohn's disease of the duodenum or upper jejunum. ${ }^{21}$

When the rate of iron supply to the developing erythroblast is limited as a result of ID, red cell haemoglobinisation would be impaired. The red cells which then emerge from the marrow are microcytic and hypochromic. The Epo response to the fall in haemoglobin will stimulate erythropoiesis further, creating an even greater demand for iron which cannot be met. As a result there is a high degree of ineffective erythropoiesis in this condition. ${ }^{22}$

\section{Iron and immunity}

Iron is essential for erythropoiesis but is an active component of many enzymes also relevant for the growth and function of other dynamic cell compartments, such as immune cells. Iron is involved in immune effector pathways of neutrophils and macrophages by formation of toxic hydroxyl radicals. Iron restriction affects the proliferation and differentiation of $\mathrm{B}$ and Thl lymphocytes, while iron overload leads to dysfunction of natural killer cells, impaired neutrophil cytotoxicity, and changes in the ratio of $\mathrm{CD}^{+}$to $\mathrm{CD}^{+}$lymphocytes. ${ }^{23}{ }^{24}$

Monocytes/macrophages have evoked different pathways by which they can acquire iron. Therefore, they are not affected as much by iron limitation. Macrophages may act as an iron storage pool which may expand in ACD. ${ }^{25} 26$ Intracellular iron availability in macrophages is important for fighting infection. The natural resistance associated macrophage protein (NRAMP-1) has been identified as a transmembrane iron transporter that confers resistance towards infection with intracellular pathogens..$^{27}$

Imbalances in iron homeostasis influence cytokine activities and cell mediated immune effector mechanisms of macrophages. High iron load reduces the responsiveness towards interferon $\gamma(\mathrm{IFN}-\gamma)$ leading to lower expression of tumour necrosis factor $\alpha$ (TNF- $\alpha)$, MHC class II antigens, neopterin, or intercellular adhesion molecule l, and to a Thl/ Th2 imbalance with Thl effector function being weakened and Th2 mediated cytokine production being increased. ${ }^{29-32}$ 
Table 1 Iron intake in patients with inflammatory bowel disease (IBD) and controls

\begin{tabular}{|c|c|c|c|c|c|c|c|c|c|}
\hline \multirow[b]{3}{*}{ Reference } & \multirow[b]{3}{*}{$\mathbf{n}$} & \multicolumn{4}{|c|}{ Iron intake $(\mathrm{mg} /$ day) $t \dagger$} & \multicolumn{4}{|c|}{ Iron density (mg/1000 kcal) } \\
\hline & & \multicolumn{2}{|l|}{ IBD } & \multicolumn{2}{|c|}{ Controls } & \multicolumn{2}{|l|}{ IBD } & \multicolumn{2}{|c|}{ Controls } \\
\hline & & Males & Females & Males & Females & Males & Females & Males & Females \\
\hline $\begin{array}{l}\text { Hodges et al } 1984^{105} \dagger \\
\text { Gee et al } 1985^{106} \ddagger \\
\text { Imes et al } 1987^{107} \S\end{array}$ & $\begin{array}{r}47 \\
64 \\
137\end{array}$ & $\begin{array}{l}17.6 \\
16.6 \\
18.0\end{array}$ & $\begin{array}{l}11.7 \\
11.4 \\
11.2\end{array}$ & $\begin{array}{l}- \\
13.5 \\
-\end{array}$ & $\begin{array}{l}- \\
9.2 \\
-\end{array}$ & $\begin{array}{l}6.4 \\
6.2 \\
6.1\end{array}$ & $\begin{array}{l}6.5 \\
6.4 \\
6.3\end{array}$ & $\begin{array}{l}- \\
6.2 \\
-\end{array}$ & $\begin{array}{l}- \\
7.2 \\
-\end{array}$ \\
\hline & & \multicolumn{2}{|c|}{ Crohn's disease } & \multicolumn{2}{|c|}{ Controls } & \multicolumn{2}{|c|}{ Crohn's disease } & \multicolumn{2}{|c|}{ Controls } \\
\hline $\begin{array}{l}\text { Geerling et al } 1998^{108} \\
\text { Lomer et al } 2004^{19 * *}\end{array}$ & $\begin{array}{l}32 \\
91\end{array}$ & \multicolumn{2}{|l|}{$\begin{array}{l}13.3 \\
9.3^{* * *}\end{array}$} & \multicolumn{2}{|l|}{$\begin{array}{l}13.5 \\
11.6\end{array}$} & \multicolumn{2}{|l|}{$\begin{array}{l}5.0 \\
4.5^{\star \star \star}\end{array}$} & \multicolumn{2}{|l|}{$\begin{array}{l}5.5 \\
5.6\end{array}$} \\
\hline \multicolumn{10}{|c|}{ 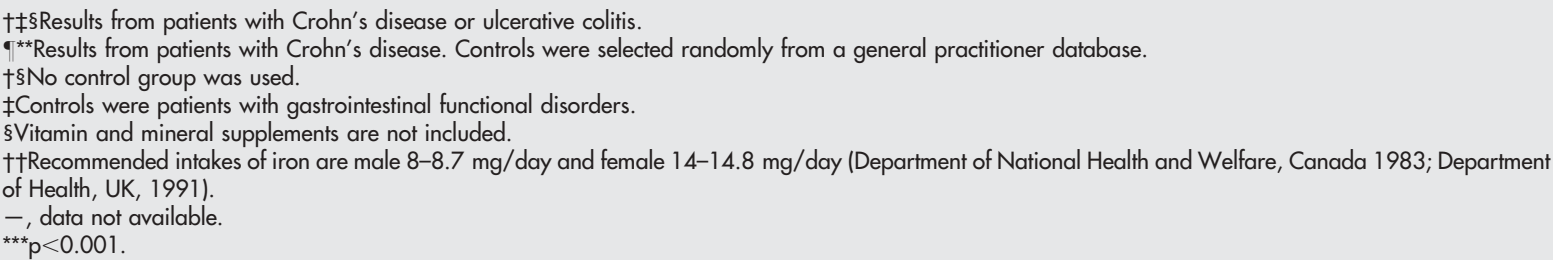 } \\
\hline
\end{tabular}

As a consequence, such macrophages loose their ability to kill intracellular pathogens by IFN- $\gamma$ mediated pathways. This can be partially explained by inhibition of transcription of inducible nitric oxide (NO) synthase, ${ }^{33} 34$ the enzyme for cytokine inducible high output formation of NO. NO is a critical molecule of macrophages for defence against infectious pathogens..$^{35} 36$

\section{"A certain amount of iron appears to be necessary for lymphocyte development but iron deposition in immune cells blocks essential immune functions and host resistance towards invading pathogens"}

Such in vitro findings are supported by clinical evidence. In human cerebral malaria, the iron chelator desferrioxamine resulted in an improved clinical course. ${ }^{37}{ }^{38}$ In contrast, patients with iron overload in Africa are at higher risk of tuberculosis. ${ }^{39}{ }^{40}$ However, patients with severe ID are also susceptible to infection. ${ }^{41}$ Thus a certain amount of iron appears to be necessary for lymphocyte development but iron deposition in immune cells blocks essential immune functions and host resistance towards invading pathogens. It is tempting to speculate that ID enhances the IFN- $\gamma$ response in Thl driven inflammation in immune mediated inflammatory disorders such as Crohn's disease.

\section{Anaemia of chronic disease}

ACD is the most frequent anaemia in hospitalised patients and develops in subjects suffering from diseases that are associated with chronic activation of cell mediated immunity, such as chronic infections, immune mediated inflammatory disorders, or malignancy. ${ }^{42}$ Thus ACD is primarily an immune driven disorder with cytokines such as TNF- $\alpha$ or IFN- $\gamma$ and acute phase proteins being the major players. Several factors contribute to the development of ACD.

\section{Diversion of iron traffic}

A hallmark of ACD is hypoferraemia, and accordingly iron limitations at the erythron, while iron is taken up by macrophages and dendritic cells of the reticuloendothelial system (RES). Thus ACD can be easily diagnosed by the presence of hypoferraemia and increased serum levels of ferritin (fig l).

Macrophages can acquire iron by multiple pathways, including transferrin receptor mediated iron uptake,

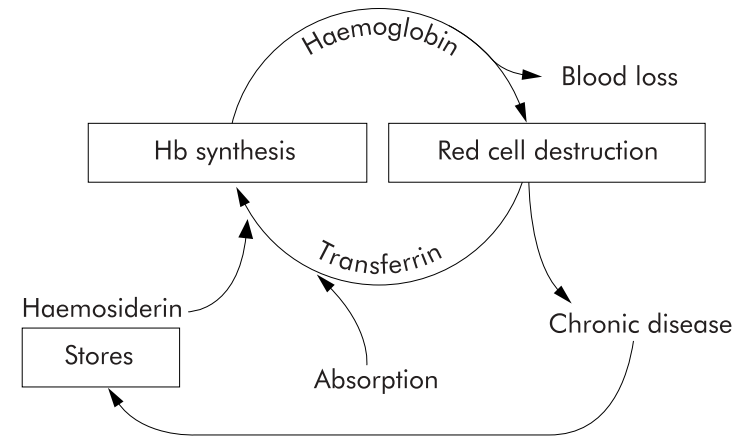

Figure 1 Iron and erythropoiesis in chronic disease. When erythropoiesis is suppressed, iron which is released at the end of the red cell lifespan and which would normally have been recycled into new haemoglobin is diverted into iron stores. As a result, serum ferritin levels are increased. Iron absorption is driven mainly by erythropoiesis. When this is suppressed, iron absorption is likewise decreased.

NRAMP-1, lactoferrin, the haemoglobin receptor, and erythrophagocytosis. ${ }^{43}$ Cytokines modulate the expression and activity of these iron uptake pathways and also cause iron retention by downregulating expression of the transmembrane iron transporter ferroportin $1 .{ }^{44} 45$ Acute phase proteins such as $\alpha_{1}$ antitrypsin block transferrin mediated iron uptake into erythroid progenitor cells but not into cells of the RES. ${ }^{46}$ The recently discovered interleukin 6 inducible peptide hepcidin downregulates iron absorption in the duodenum and may interfere with iron release from cells of the RES. ${ }^{47}$

\section{Inhibition of erythroid progenitor proliferation and differentiation}

Apart from modulating iron homeostasis, cytokines directly affect erythropoiesis by inhibiting the growth of erythroid progenitor cells. TNF- $\alpha$ and type I and II interferons block BFU-e and CFU-e colony formation ${ }^{48}$ and IFN- $\gamma$ appears to be the most potent inhibitor of erythropoiesis in directly blocking CFU-e proliferation. ${ }^{49}$ The latter is nicely reflected by an inverse correlation between IFN- $\gamma$ levels and haemoglobin concentration and reticulocyte counts in ACD patients. ${ }^{50} \mathrm{NO}$ may directly block erythropoiesis by inhibition of erythroid progenitor cell proliferation and haeme biosynthesis. $^{51} 52$ 


\section{Blunted Epo response}

Serum Epo levels in patients with ACD appear to be inadequately low for the degree of anaemia. However, this does not hold true for all diseases underlying $\mathrm{ACD}^{53}$ but has been shown for Crohn's disease and ulcerative colitis. ${ }^{54}{ }^{55}$ In fact, cytokines may directly inhibit Epo production in the kidney. ${ }^{56}$ Moreover, Epo responsiveness of erythroid progenitor cells may be associated with the severity of disease and the degree of immune activation. In vitro, in the presence of IFN $-\gamma$ or TNF- $\alpha$, higher amounts of Epo are needed to restore CFU-e colony formation. ${ }^{57}$

\section{Erythrocyte life cycle}

Application of sublethal doses of TNF- $\alpha$ or endotoxin to mice reduces red blood cell (RBC) half life, decreases the incorporation of iron, induces hypoferraemia, and causes anaemia. ${ }^{58}$ Stimulation of erythrophagocytosis is also reflected by increased amounts of erythrocyte derived iron in splenic macrophages and Kupffer cells under inflammatory conditions. ${ }^{59}$

\section{Vitamin B 12 and folate deficiency}

Vitamin B12 (or cobalamin) and folic acid are vitamins and coenzymes involved in a series of complex biochemical reactions, including DNA synthesis.

Clinical evidence of Vitamin B12 deficiency occurs late as body stores have to be depleted to less than $10 \%$. Vitamin B12, which is bound to the stomach derived intrinsic factor, is primarily absorbed in the terminal ileum. Chronic ileal inflammation or resection, particularly in Crohn's disease, may give rise to deficiency and clinical symptoms. An association with gastric Crohn's disease had also been recognised..$^{60}$ Folate is absorbed in the duodenum and jejunum and deficiency may be due to inadequate diet, malabsorption, or drug interactions (sulphasalazine, methotrexate). Clinical manifestation occurs earlier as folate stores last only $1-2$ months.

\section{Anaemia due to treatment}

Apart from folate deficiency, therapy with sulphasalazine or 5 -aminosalicylic acid has been related to a minor degree of haemolysis or aplasia. ${ }^{61-64}$ More importantly, both 6-mercaptopurine and azathioprine have a direct myelosuppressive effect. The risk of developing leucopenia or aplasia is high in individuals with low thiopurine methyltransferase (TPMT) activity. ${ }^{65}$ The enzyme activity of TPMT is genetically determined and genotyping has been suggested as a means of detecting patients at risk. ${ }^{66}$ In clinical practice, however, concerns have been raised about the predictive accuracy of this test. ${ }^{67} 68$

There are many other less common causes of anaemia in IBD (reviewed by Schreiber and $\mathrm{Wedel}^{69}$ ) which are best dealt with by those who see them more frequently, such as the local haematologist (table 2).

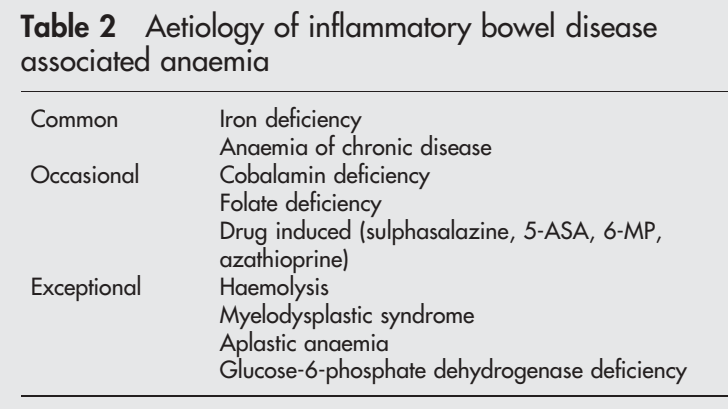

\section{DIAGNOSTIC TESTS}

Monitoring of IBD patients with complete blood counts is a routine measure. The lower haemoglobin cut off level in women $(12.0 \mathrm{~g} / \mathrm{dl} v 13.5 \mathrm{~g} / \mathrm{dl}$ in men) may fail to trigger doctors to provide adequate therapy when needed. Of course, menstruating women lose more blood than their male counterparts and are therefore at higher risk of ID. The consequence of this biological fact should be superior care for haemoglobin and iron stores in menstruating or pregnant women and not a lower treatment trigger.

\section{"Monitoring of IBD patients with complete blood counts is a routine measure"}

Red cell size is reflected in mean cell volume (MCV) and mean cell haemoglobin, which allow a first diagnostic clue. Hypochromia and microcytosis indicate red cell ID with or without concomitant ACD. Macrocytosis points to a vitamin B12 or folic acid deficiency. An increase in MCV without significant anaemia is useful in monitoring treatment response or compliance during azathioprine or 6-mercaptopurine therapy. ${ }^{70}$ Apart from a complete blood count, iron parameters need to be checked regularly. Measurement of serum ferritin reflects the level of iron in stores. When serum ferritin is less than $15 \mu \mathrm{g} / \mathrm{l}$, iron stores are definitely depleted. When ferritin is above $20 \mu \mathrm{g} / \mathrm{l}$, there is iron in the stores but it may be insufficient to meet the demands of the proliferating progenitors of red cells, and this is true even up to levels of $700 \mu \mathrm{g} / \mathrm{l}^{71} \mathrm{C}$ reactive protein is useful to estimate the level of inflammation.

Further evaluation may include reticulocyte counts, vitamin B12, and folic acid. The per cent hypochromic RBC and reticulocyte haemoglobin content have been proposed for evaluation of functional ID during Epo therapy. ${ }^{72}{ }^{73}$

Because of different therapeutic consequences, it is important to distinguish ACD from ID. Patients with "classical" ACD present with increased ferritin levels while transferrin concentrations as well as transferrin saturation are reduced. In contrast, all of these parameters are decreased in ACD patients with ID. Pure ID is recognised by low ferritin and transferrin saturation but increased transferrin concentrations. The ratio of soluble transferrin receptor/log ferritin has been proposed for differential diagnosis of these overlapping conditions. ${ }^{74}$ In IBD patients, high levels of serum transferrin, soluble transferrin receptor, and serum Epo predict response to intravenous iron supplementation and low levels indicate a need for concomitant Epo therapy. ${ }^{75}$

\section{QUALITY OF LIFE: THE THERAPEUTIC GOAL}

The ultimate therapeutic goal is improvement in quality of life but the only objective measure we have to hand is change in haemoglobin concentration. Quality of life improvements of anaemic cancer patients were detected at haemoglobin levels of up to $14 \mathrm{~g} / \mathrm{dl} .{ }^{11}$ As most IBD patients are young, they may have even higher physical and cognitive demands than cancer patients. Normalisation of haemoglobin level $(12.0 \mathrm{~g} / \mathrm{dl}$ in women and $13.5 \mathrm{~g} / \mathrm{dl}$ in men) should be sought.

The mechanisms of IBD associated anaemia involve particularly ID and ACD. In cases of vitamin B12 or folic acid deficiency, appropriate substitution is needed. This leaves the major problem of directing iron therapy and improving erythropoiesis in chronic disease.

\section{Iron supplementation}

\section{Oral iron preparations}

Oral iron supplements commonly contain iron in the form of ferrous salts (ferrous sulphate, ferrous gluconate, and ferrous fumarate). All ferrous compounds are oxidised in the lumen of the gut or within the mucosa with release of activated 
hydroxyl radicals, which will attack the gut wall and produce a range of gastrointestinal symptoms and discomfort. ${ }^{76} 77$ Enteric coated ferrous formulations attempt to avoid this by minimising iron release in the stomach. If this is successful it also prevents iron absorption.

\section{"Because there is no excretory route, iron homeostasis in organisms is regulated at the level of iron uptake"}

Because there is no excretory route, iron homeostasis in organisms is regulated at the level of iron uptake. If iron absorption is not tightly regulated, iron overload and associated toxicity occurs such as seen in hereditary haemochromatosis. Another obstacle of oral iron supplementation is therefore the limited capacity of iron absorption. The efficacy of oral iron therapy in patients with IBD may be further hindered by some IBD specific factors. Firstly, gastrointestinal side effects of oral ferrous iron such as nausea, bloating, diarrhoea, or upper gastrointestinal pain are more pronounced compared with those observed in non-IBD patients taking oral iron therapy. ${ }^{78}$ Secondly, in chronic inflammatory disease, absorption of iron appears to be reduced which would limit the growth of microbes in chronic infections. ${ }^{79}$ The acute phase protein hepcidin may play a central role in this as its overexpression in the liver leads to decreased iron uptake by the duodenum. ${ }^{47}$ Thirdly, body iron distribution is altered. Most of the iron that is absorbed is directed into the RES while only minor amounts may reach the sites of erythropoiesis.

Ferric iron polymaltose complex, ferric trimaltol, or haeme iron polypeptide are also available in some countries. Ferric iron has less pro-oxidant potential but is sparingly insoluble and generally biounavailable. Surprisingly, in an open study, oral administration of ferric trimaltol complexes has been found to be safe and effective. ${ }^{80}$ The newer non-ionic iron polymaltose has been shown to have no oxidative potency on lipoproteins in healthy subjects ${ }^{81}$ and a better compliance than ferrous sulphate but data on efficacy are lacking. ${ }^{82}$ Haeme iron polypeptide takes advantage of alternative absorption pathways. This product is thought to have improved bioavailability ${ }^{83}$ and promises lower side effects but has an animal origin and larger series have not yet been treated.

\section{Intravenous iron preparations}

The limitations of oral iron therapy in IBD patients mean that alternative routes of iron administration must be considered. Direct administration of iron into the circulation requires formulations that prevent the cellular toxicity of iron salts. ${ }^{84}$ Three different products are currently available:

Iron dextran is a stable parenteral iron product with a molecular weight of 100-500 kDa. These iron complexes show high structural homogeneity and only slow and competitive delivery to endogenous iron binding proteins. Complexes are actively phagocytosed by macrophages of the RES before they are released and become available for haemoglobin synthesis. Plasma half life is $3-4$ days. The stability of the dextran complex allows administration of high single doses (so called "total dose therapy"). The molecule however may cause well know dextran induced anaphylactic reactions.

Iron gluconate is a labile type with fast degradation kinetics and direct release to plasma proteins (apotransferrin, apoferritin, and others). Potential toxicity of iron gluconate is caused by oversaturation of the transferrin binding capacity. ${ }^{85}$ Non-transferrin bound free ionic iron may induce acute endothelial cell injury and a transient capillary leak syndrome. Clinical symptoms in such circumstances include nausea, hypotension, tachycardia, dyspnoea (lung oedema), and bilateral oedema of the hands and feet, and should not be misread as anaphylaxis. The use of iron gluconate for iron deficiency in patients on dialysis has been found to be safe and superior to iron dextran..$^{86}$

Iron sucrose (previously referred to as iron saccharate) is much smaller than iron dextran (34-60 kDa) and carries no risk of dextran induced anaphylactic reactions. Iron sucrose is a partially stable type with medium degradation kinetics and partial uptake of released iron by plasma proteins such as (apo)-transferrin but also by the RES. Its half life is relatively short (5-6 hours). ${ }^{88}$

During the last few years, experience of using iron sucrose in various forms of ID has evolved ${ }^{88}$ Single doses of up to $300 \mathrm{mg}$ are safe. ${ }^{89}$ The maximal recommended dosage is $600 \mathrm{mg} /$ week but this amount exceeds the physiological needs of the proliferating erythroblast. ${ }^{89}$ If the infusion speed is too fast (above $4 \mathrm{mg} \mathrm{Fe}^{3+} / \mathrm{min}$ ) or the single total iron dose too high (above $7 \mathrm{mg} \mathrm{Fe}^{3+} / \mathrm{kg}$ ), non-transferrin bound free iron may cause transient hypotension, tachycardia, and dyspnoea, as described for iron gluconate. Increased levels of non-transferrin bound iron have been detected in asymptomatic haemodialysis patients following iron sucrose injections which may potentially promote atherosclerosis. ${ }^{90}$

More than 1000 infusions have been given in trials in IBD associated anaemia without major side effects, using $200 \mathrm{mg}$ iron sucrose, diluted in $250 \mathrm{ml}$ of $0.9 \%$ sodium chloride, twice weekly during the first two weeks and once weekly thereafter. $^{125575}$ After $1200 \mathrm{mg}$ of iron sucrose (four weeks) approximately $65 \%$ and after $2000 \mathrm{mg}$ (eight weeks) approximately $75 \%$ of patients responded (fig 2 ). Iron sucrose has also been safely used after the first trimester of pregnancy and postpartum..$^{1-93}$

In general, the intramuscular or subcutaneous routes of parenteral iron administration are obsolete because of the increase in side effects and decrease in efficacy.

\section{Iron therapy and intestinal inflammation}

As iron homeostasis and cellular immunity are closely linked, it is suggestive that the different therapeutic regimens of iron supplementation may have subtle effects on immune function and intestinal inflammation in IBD. As outlined above, iron inhibits IFN- $\gamma$ activity and thereby has deactivating effects on macrophage function and the Thl response. Thus intravenous iron therapy could ease Thl driven intestinal inflammation in Crohn's disease. Although specific data in Crohn's disease are missing, this notion is supported by the fact that (i) intravenous iron supplementation to anaemic dialysis patients significantly reduced circulating levels of TNF- $\alpha$ and peroxides ${ }^{94}$ and (ii) combined treatment of anaemia in subjects with active rheumatoid arthritis with iron and Epo significantly reduced disease activity. ${ }^{95}$

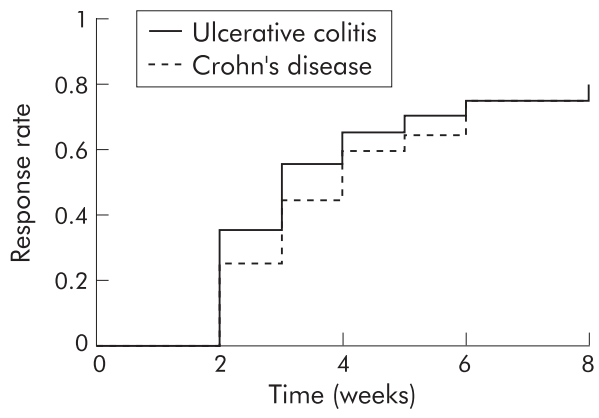

Figure 2 Response to iron sucrose in ulcerative colitis and Crohn's disease. A total of $2 \mathrm{~g}$ of iron sucrose were given intravenously within eight weeks: $400 \mathrm{mg}$ /week during the first two weeks and $200 \mathrm{mg} /$ week thereafter. Response was defined as increase in haemoglobin of equal to or above $2 \mathrm{~g} / \mathrm{dll}$. Data were collected from two trials. ${ }^{1255}$ 
"Oral iron may induce oxidative stress within the lumen of the gut"

Oral iron may induce oxidative stress within the lumen of the gut. This mechanism increases the intestinal production of proinflammatory cytokines in rodent models of IBD and was the hypothesis for studying iron chelation therapy in Crohn's disease. ${ }^{96}{ }^{97}$ Most of the ingested ferrous iron is not absorbed but is passed on to the ileum and colon, sites of inflammation in Crohn's disease and ulcerative colitis, before appearing in the stool. When iron attaches to the ulcerated intestinal surface, it may increase local production of reactive oxygen species and thereby enhance inflammation. This has been demonstrated in animal models of IBD ${ }^{96}$ as well as in patients with Crohn's disease. ${ }^{78}$

Although there are no data at present, we do not expect an intestinal increase in oxidative stress from intravenous iron products because ferric iron does not have an oxidative potential and the route of administration does not favour intestinal accumulation.

\section{Recombinant human Epo}

Specific drugs for the treatment of ACD have not yet been developed. Anti-inflammatory drugs may inhibit cytokine production but may also inhibit erythropoiesis (for example, azathioprine). Although theoretically anti-TNF and anti-IFN- $\gamma$ strategies such as infliximab or natalizumab may specifically counteract ACD driven erythropoietic inhibition, ${ }^{98}$ such effects have not been reported in clinical trials in IBD.

Supraphysiological doses of Epo can overcome the inhibition of erythropoiesis in ACD, which is the rationale for Epo therapy.$^{57}$ Epo has been studied in a variety of different types of ACD. ${ }^{99}{ }^{100}$ In IBD, successful treatment was reported after restoration of iron stores. ${ }^{101}$ Double blinded controlled trials followed, with either oral ${ }^{102}$ or intravenous ${ }^{12}$ iron supplementation (fig 3). All trials demonstrated a significant effect of Epo on haemoglobin increase. Epo treatment of iron refractory cases with IBD associated anaemia also proved to be safe and effective in children. ${ }^{103}$ The specificity of the Epo downstream events limits the array of possible adverse events. Thrombosis, hypertension, and seizures have been rarely observed in patients with renal failure and are likely due to the underlying rise in haematocrit and total blood volume. Next generation Epo analogues, such as the novel erythropoiesis stimulating protein (NESP), have a longer serum half life but a decreased binding affinity to the Epo

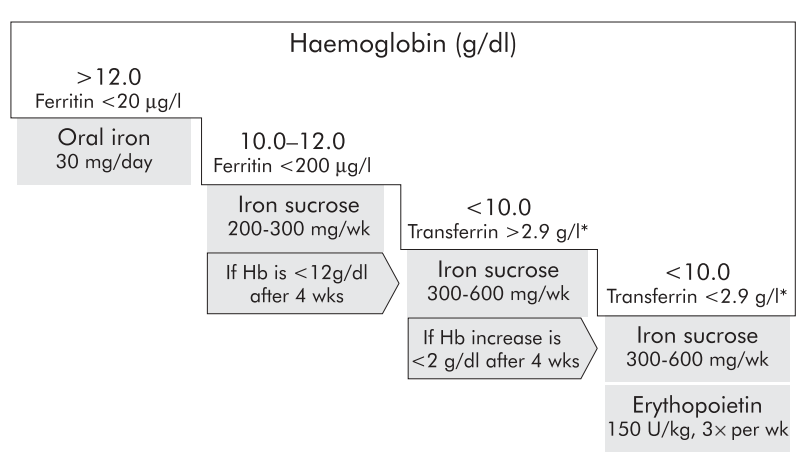

Figure 4 Adjusting therapy to the degree of anaemia. The place of oral iron therapy is mainly prevention of iron deficiency anaemia. In patients with normocytic or microcytic anaemia, iron sucrose demonstrates the best efficacy and tolerability. The amount of iron needed relates to the degree of anaemia and can be estimated using the approximation that an increase of $1 \mathrm{~g} / \mathrm{dl}$ haemoglobin $(\mathrm{Hb})$ requires about $200 \mathrm{mg}$ of intravenous iron. It is recommend that iron therapy is suspended in cases of acute infection (for example, abscess) or at a transferrin saturation $>50 \%$. *Instead of transferrin, the soluble transferrin receptor (below $50 \mathrm{nmol} / \mathrm{l}$ ) or erythropoietin concentration (below $100 \mathrm{U} / \mathrm{l}$ ) can be applied.

receptor. ${ }^{104}$ We are not aware of any studies that have been performed in IBD.

As iron sucrose was found to be highly effective on its own, Epo was spared for those cases who primarily failed on iron sucrose alone..$^{55}$ In an attempt to identify parameters that predict failure of iron sucrose therapy, plasma Epo levels, soluble transferrin receptor, and transferrin concentrations were studied. ${ }^{75}$ Low Epo (below $100 \mathrm{U} / \mathrm{l}$ ), soluble transferrin receptor (below $50 \mathrm{nmol} / \mathrm{l}$ ), or transferrin levels (below $2.9 \mathrm{~g} / \mathrm{l}$ ) strongly indicated resistance to iron sucrose. However, it is our experience that virtually all patients with IBD associated anaemia can be successfully treated with the combination of iron sucrose and Epo (fig 4).

"Until we cure IBD, our prime goal is optimisation of supportive care in order to enhance the patient's quality of life"

When dealing with IBD patients, there are good reasons to pay more attention to iron metabolism and erythropoiesis
A

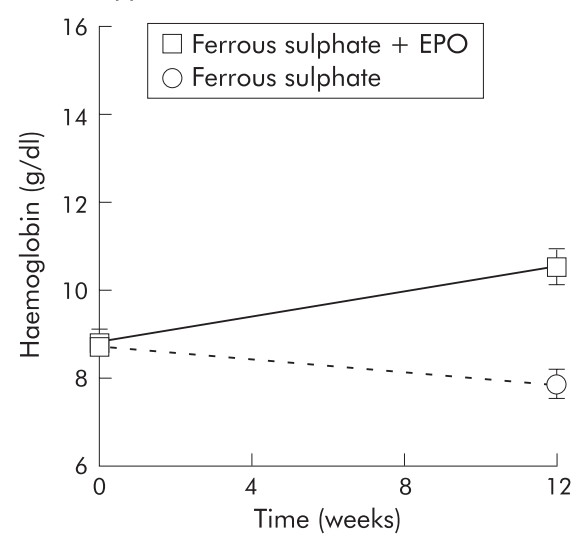

B

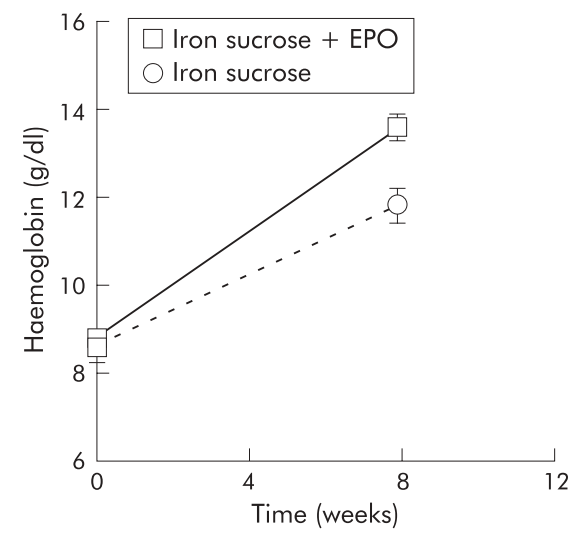

Figure 3 Iron sucrose versus ferrous sulphate for inflammatory bowel disease associated anaemia. Two controlled studies, both of which were demonstrating the effect of erythropoietin (Epo) in IBD associated anaemia, are outlined. Baseline haemoglobin levels and total Epo dosage were identical. In one trial (A), ferrous sulphate was used for iron supplementation ${ }^{102}$ and in the other (B) iron sucrose was given. ${ }^{12}$ On ferrous sulphate alone, $100 \mathrm{mg} /$ day, mean haemoglobin level dropped over the 12 week study period. In contrast, iron sucrose caused a considerable haemoglobin increase that was faster and larger when combined with Epo. 
than ever before. Anaemia in IBD is still a frequent complication that affects the ability to perform normal daily activities, but the tools to effectively prevent or treat anaemia have been identified and are readily available. Until we cure IBD, our prime goal is optimisation of supportive care in order to enhance the patient's quality of life. Aiming for anaemia treatment in IBD is rewarding for both the patient and the caring physician.

\section{ACKNOWLEDGEMENTS}

CG received grants from the Austrian Science Fund (P15314) and the OeNB Anniversary Fund (ONB10543). MCEL is supported by the PPP Foundation and the DH NHS R\&D Programme.

\section{Authors' affiliations}

C Gasche, Department of Medicine 4, Division of Gastroenterology and Hepatology, Medical University Vienna, Austria

M C E Lomer, Gastrointestinal Laboratory, the Rayne Institute, St. Thomas' Hospital, London, UK

I Cavill, Department of Haematology, University of Wales, College of Medicine, Cardiff, UK

G Weiss, Department of General Internal Medicine, Clinical Immunology and Infectious Diseases, University of Innsbruck, Austria

\section{REFERENCES}

1 Oldenburg B, Koningsberger JC, Berge Henegouwen GP, et al. Iron and inflammatory bowel disease. Aliment Pharmacol Ther 2001;15:429-38.

2 Gasche C. Anemia in IBD: the overlooked villain. Inflamm Bowel Dis 2000;6:142-50.

3 Macdougall IC. Quality of life and anemia: the nephrology experience. Semin Oncol 1998;25(suppl 7):39-42.

4 Vatner SF. Effects of hemorrhage on regional blood flow distribution in dogs and primates. J Clin Invest 1974;54:225-35.

5 Daneryd P, Svanberg E, Korner U, et al. Protection of metabolic and exercise capacity in unselected weight-losing cancer patients following treatment with recombinant erythropoietin: a randomized prospective study. Cancer Res 1998;58:5374-9.

6 Ludwig H, Strasser K. Symptomatology of anemia. Semin Oncol 2001;28(suppl 8):7-14.

7 Pickett JL, Theberge DC, Brown WS, et al. Normalizing hematocrit in dialysis patients improves brain function. Am J Kidney Dis 1999;33:1122-30.

8 Bruner AB, Joffe A, Duggan AK, et al. Randomised study of cognitive effects of iron supplementation in non-anaemic iron-deficient adolescent girls. Lancet 1996;348:992-6.

9 Mitchell A, Guyatt G, Singer J, et al. Quality of life in patients with inflammatory bowel disease. J Clin Gastroenterol 1988;10:306-10.

10 Demetri GD, Kris M, Wade J, et al. Quality-of-life benefit in chemotherapy patients treated with epoetin alfa is independent of disease response or tumor type: results from a prospective community oncology study. Procrit Study Group. J Clin Oncol 1998;16:3412-25.

11 Crawford J, Cella D, Cleeland CS, et al. Relationship between changes in hemoglobin level and quality of life during chemotherapy in anemic cancer patients receiving epoetin alfa therapy. Cancer 2002;95:888-95.

12 Gasche C, Dejaco C, Waldhoer T, et al. Intravenous iron and erythropoietin for anemia associated with Crohn disease. A randomized, controlled trial. Ann Intern Med 1997;126:782-7.

13 Leitgeb C, Pecherstorfer M, Fritz E, et al. Quality of life in chronic anemia of cancer during treatment with recombinant human erythropoietin. Cancer 1994;73:2535-42.

14 Curt GA. Impact of fatigue on quality of life in oncology patients. Semin Hematol 2000;37(suppl 6):14-17.

15 Monsen ER, Hallberg L, Layrisse M, et al. Estimation of available dietary iron. Am J Clin Nutr 1978;31:134-41.

16 Parkkila S, Niemela O, Britton RS, et al. Molecular aspects of iron absorption and HFE expression. Gastroenterology 2001;121:1489-96.

17 Mishkin S. Dairy sensitivity, lactose malabsorption, and elimination diets in inflammatory bowel disease. Am J Clin Nutr 1997;65:564-7.

18 Ballegaard M, Bjergstrom A, Brondum S, et al. Self-reported food intolerance in chronic inflammatory bowel disease. Scand J Gastroenterol 1997:32:569-71.

19 Lomer MC, Kodjabashia K, Hutchinson C, et al. Intake of dietary iron is low in patients with Crohn's disease: a case-control study. Br J Nutr 2004;91:141-8

20 Child JA, Brozovic B, Dyer NH, et al. The diagnosis of iron deficiency in patients with Crohn's disease. Gut 1973;14:642-8.

21 Bartels U, Pedersen NS, Jarnum S. Iron absorption and serum ferritin in chronic inflammatory bowel disease. Scand J Gastroenterol 1978;13:649-56.

22 Cavill I. Erythropoiesis and iron. Best Pract Res Clin Haematol 2002; 15:399-409.

23 Seligman PA, Kovar J, Gelfand EW. Lymphocyte proliferation is controlled by both iron availability and regulation of iron uptake pathways. Pathobiology 1992;60:19-26.
24 de Sousa M. Immune cell functions in iron overload. Clin Exp Immunol 1989;75: 1-6.

25 Brock JH. Iron in infection, immunity, inflammation and neoplasia. In: Brock JH, Halliday JW, Pippard MJ, et al. Iron metabolism in health and disease. Philadelphia: WB Saunders Co Ltd, 1994:353-91.

26 Weiss G. Iron acquisition by the reticuloendothelial system. In: Templeton D, eds. Molecular and cellular iron transport. New York: Marcel Decker Inc, 2002:468-87

27 Forbes JR, Gros P. Divalent-metal transport by NRAMP proteins at the interface of host-pathogen interactions. Trends Microbiol $2001 ; 9: 397-403$.

28 Blackwell JM, Searle S, Goswami T, et al. Understanding the multiple functions of Nrampl. Microbes Infect 2000;2:317-21.

29 Weiss $G$, Fuchs D, Hausen A, et al. Iron modulates interferon-gamma effects in the human myelomonocytic cell line THP-1. Exp Hematol 1992;20:605-10.

30 Recalcati S, Pometta R, Levi S, et al. Response of monocyte iron regulatory protein activity to inflammation: abnormal behavior in genetic hemochromatosis. Blood 1998;91:2565-72.

31 Oexle H, Kaser A, Most J, et al. Pathways for the regulation of interferongamma-inducible genes by iron in human monocytic cells. J Leukoc Biol 2003;74:287-94.

32 Mencacci A, Cenci E, Boelaert JR, et al. Iron overload alters innate and T helper cell responses to Candida albicans in mice. J Infect Dis 1997; 175:1467-76

33 Weiss G, Werner-Felmayer G, Werner ER, et al. Iron regulates nitric oxide synthase activity by controlling nuclear transcription. J Exp Med 1994; 180:969-76.

34 Melillo G, Taylor LS, Brooks A, et al. Functional requirement of the hypoxiaresponsive element in the activation of the inducible nitric oxide synthase promoter by the iron chelator desferrioxamine. J Biol Chem 1997;272: 12236-43.

35 MacMicking J, Xie QW, Nathan C. Nitric oxide and macrophage function. Annu Rev Immunol 1997; 15:323-50.

36 Bogdan C. Nitric oxide and the immune response. Nat Immunol 2001;2:907-16.

37 Fritsche G, Larcher C, Schennach $\mathrm{H}$, et al. Regulatory interactions between iron and nitric oxide metabolism for immune defense against Plasmodium falciparum infection. J Infect Dis 2001;183:1388-94.

38 Gordeuk V, Thuma P, Brittenham G, et al. Effect of iron chelation therapy on recovery from deep coma in children with cerebral malaria. $N$ Engl I Med 1992;327:1473-7.

39 Gomes MS, Boelaert JR, Appelberg R. Role of iron in experimental Mycobacterium avium infection. J Clin Virol 2001;20:117-22.

40 Gordeuk VR, McLaren CE, MacPhail AP, et al. Associations of iron overload in Africa with hepatocellular carcinoma and tuberculosis: Strachan's 1929 thesis revisited. Blood 1996;87:3470-6.

41 Jason J, Archibald LK, Nwanyanwu OC, et al. The effects of iron deficiency on lymphocyte cytokine production and activation: preservation of hepatic iron but not at all cost. Clin Exp Immunol 2001;126:466-73.

42 Weiss G. Pathogenesis and treatment of anaemia of chronic disease. Blood Rev 2002;16:87-96.

43 Moura E, Verheul AF, Marx JJ. A functional defect in hereditary haemochromatosis monocytes and monocyte-derived macrophages. Eur J Clin Invest 1998;28:164-73.

44 Ludwiczek S, Aigner E, Theurl I, et al. Cytokine-mediated regulation of iron transport in human monocytic cells. Blood 2003;101:4148-54.

45 Yang $F$, Liu XB, Quinones $M$, et al. Regulation of reticuloendothelial iron transporter MTP1 (Slcl la3) by inflammation. J Biol Chem 2002;277:39786-91.

46 Graziadei I, Gaggl S, Kaserbacher R, et al. The acute-phase protein alpha 1antitrypsin inhibits growth and proliferation of human early erythroid progenitor cells (burst-forming units-erythroid) and of human erythroleukemic cells (K562) in vitro by interfering with transferrin iron uptake. Blood 1994;83:260-8.

47 Ganz T. Hepcidin, a key regulator of iron metabolism and mediator of anemia of inflammation. Blood 2003;102:783-8.

48 Means RTJ, Krantz SB. Progress in understanding the pathogenesis of the anemia of chronic disease. Blood 1992;80:1639-47.

49 Wang CQ, Udupa KB, Lipschitz DA. Interferon-gamma exerts its negative regulatory effect primarily on the earliest stages of murine erythroid progenitor cell development. J Cell Physiol 1995;162:134-8.

50 Fuchs D, Hausen A, Reibnegger G, et al. Immune activation and the anaemia associated with chronic inflammatory disorders. Eur J Haematol 1991:46:65-70.

51 Maciejewski JP, Selleri C, Sato T, et al. Nitric oxide suppression of human hematopoiesis in vitro. Contribution to inhibitory action of interferon-gamma and tumor necrosis factor-alpha. J Clin Invest 1995;96:1085-92.

52 Rafferty SP, Domachowske JB, Malech HL. Inhibition of hemoglobin expression by heterologous production of nitric oxide synthase in the K562 erythroleukemic cell line. Blood 1996;88:1070-8.

53 Cazzola M, Ponchio L, de Benedetti F, et al. Defective iron supply for erythropoiesis and adequate endogenous erythropoietin production in the anemia associated with systemic-onset juvenile chronic arthritis. Blood 1996;87:4824-30

54 Gasche C, Reinisch W, Lochs H, et al. Anemia in Crohn's disease. Importance of inadequate erythropoietin production and iron deficiency. Dig Dis Sci 1994:39:1930-4.

55 Gasche C, Dejaco C, Reinisch W, et al. Sequential treatment of anemia in ulcerative colitis with intravenous iron and erythropoietin. Digestion 1999;60:262-7 
56 Faquin WC, Schneider TJ, Goldberg MA. Effect of inflammatory cytokines on hypoxia-induced erythropoietin production. Blood 1992;79:1987-94.

57 Means RTJ, Krantz SB. Inhibition of human erythroid colony-forming units by gamma interferon can be corrected by recombinant human erythropoietin. Blood 1991;78:2564-7.

58 Moldawer LL, Marano MA, Wei H, et al. Cachectin/tumor necrosis factoralpha alters red blood cell kinetics and induces anemia in vivo. FASEB J 1989;3:1637-43.

59 Fillet G, Beguin Y, Baldelli L. Model of reticuloendothelial iron metabolism in humans: abnormal behavior in idiopathic hemochromatosis and in inflammation. Blood 1989;74:844-51.

60 Kraus J, Schneider R. Pernicious anemia caused by Crohn's disease of the stomach. Am J Gastroenterol 1979;71:202-5.

61 Laidlaw ST, Reilly JT. Antilymphocyte globulin for mesalazine-associated aplastic anaemia. Lancet 1994;343:981-2.

62 Anttila PM, Valimaki M, Pentikainen PJ. Pure-red-cell aplasia associated with sulphasalazine but not 5-aminosalicylic acid. Lancet 1985;2:1006.

63 van Hees PA, van Elferen LW, van Rossum JM, et al. Hemolysis during salicylazosulfapyridine therapy. Am J Gastroenterol 1978;70:501-5.

64 Bernstein CN, Artinian L, Anton PA, et al. Low-dose 6-mercaptopurine in inflammatory bowel disease is associated with minimal hematologic toxicity. Dig Dis Sci 1994;39:1638-41.

65 Black AJ, McLeod HL, Capell HA, et al. Thiopurine methyltransferase genotype predicts therapy-limiting severe toxicity from azathioprine. Ann Intern Med 1998;129:716-18.

66 Colombel JF, Ferrari N, Debuysere H, et al. Genotypic analysis of thiopurine S-methyltransferase in patients with Crohn's disease and severe myelosuppression during azathioprine therapy. Gastroenterology 2000; 118:1025-30

67 Gearry RB, Barclay ML, Burt MJ, et al. Thiopurine S-methyltransferase (TPMT) genotype does not predict adverse drug reactions to thiopurine drugs in patients with inflammatory bowel disease. Aliment Pharmacol Ther 2003; 18:395-400.

68 Lennard L. TPMT in the treatment of Crohn's disease with azathioprine. Gut 2002;51:143-6.

69 Schreiber S, Wedel S. Diagnosis and treatment of anemia in inflammatory bowel disease. Inflamm Bowel Dis 1997;3:204-16.

70 Decaux G, Prospert F, Horsmans $Y$, et al. Relationship between red cell mean corpuscular volume and 6-thioguanine nucleotides in patients treated with azathioprine. J Lab Clin Med 2000;135:256-62.

71 Eschbach JW, Downing MR, Egrie JC, et al. USA multicenter clinical trial with recombinant human erythropoietin (Amgen). Results in hemodialysis patients. Contrib Nephrol 1989;76:160-5.

72 Fishbane S, Galgano C, Langley RC jr, et al. Reticulocyte hemoglobin content in the evaluation of iron status of hemodialysis patients. Kidney Int 1997;52:217-22.

73 Fishbane $S$, Shapiro W, Dutka $P$, et al. A randomized trial of iron deficiency testing strategies in hemodialysis patients. Kidney Int 2001;60:2406-11.

74 Punnonen K, Irjala K, Rajamaki A. Serum transferrin receptor and its ratio to serum ferritin in the diagnosis of iron deficiency. Blood 1997;89:1052-7.

75 Gasche C, Waldhoer T, Feichtenschlager T, et al. Prediction of response to iron sucrose in inflammatory bowel disease-associated anemia. Am J Gastroenterol 2001;96:2382-7.

76 Babbs CF. Oxygen radicals in ulcerative colitis. Free Radic Biol Med 1992;13:169-81.

77 Millar AD, Rampton DS, Blake DR. Effects of iron and iron chelation in vitro on mucosal oxidant activity in ulcerative colitis. Aliment Pharmacol Ther 2000;14:1163-8.

78 Erichsen K, Hausken T, Ulvik RJ, et al. Ferrous fumarate deteriorated plasma antioxidant status in patients with Crohn disease. Scand J Gastroenterol 2003:38:543-8.

79 Naveh Y, Shalata A, Shenker L, et al. Absorption of iron in rats with experimental enteritis. Biometals 2000;13:29-35.

80 Harvey RS, Reffitt DM, Doig LA, et al. Ferric trimaltol corrects iron deficiency anaemia in patients intolerant of iron. Aliment Pharmacol Ther $1998 ; 12: 845-8$

81 Tuomainen T, Nyyssonen K, Porkkala-Sarataho E, et al. Oral supplementation with ferrous sulfate but not with non-ionic iron polymaltose complex increases the susceptibility of plasma lipoproteins to oxidation. Nutr Res 1999;19:1121-32.

82 Jacobs P, Wood L, Bird AR. Erythrocytes: better tolerance of iron polymaltose complex compared with ferrous sulphate in the treatment of anaemia. Hematology 2000;5:77-83

83 Seligman PA, Moore GM, Schleicher RB. Clinical studies of HIP: an oral heme-iron product. Nutr Res 2000;20:1279-86.
84 Geisser P, Baer M, Schaub E. Structure/histotoxicity relationship of parenteral iron preparations. Arzneimittelforschung 1992;42:1439-52.

85 Zanen AL, Adriaansen HJ, van Bommel EF, et al. 'Oversaturation' of transferrin after intravenous ferric gluconate (Ferrlecit(R)) in haemodialysis patients. Nephrol Dial Transplant 1996;11:820-4.

86 Fishbane S, Wagner J. Sodium ferric gluconate complex in the treatment of iron deficiency for patients on dialysis. Am J Kidney Dis 2001;37:879-83.

87 Michael B, Coyne DW, Fishbane S, et al. Sodium ferric gluconate complex in hemodialysis patients: adverse reactions compared to placebo and iron dextran. Kidney Int 2002;61:1830-9.

88 Yee J, Besarab A. Iron sucrose: the oldest iron therapy becomes new. Am J Kidney Dis 2002;40:1111-21.

89 Chandler G, Harchowal J, Macdougall IC. Intravenous iron sucrose: establishing a safe dose. Am J Kidney Dis 2001;38:988-91.

90 Kooistra MP, Kersting S, Gosriwatana l, et al. Nontransferrin-bound iron in the plasma of haemodialysis patients after intravenous iron saccharate infusion. Eur J Clin Invest 2002;32(suppl 1):36-41.

91 Breymann C, Visca E, Huch R, et al. Efficacy and safety of intravenously administered iron sucrose with and without adjuvant recombinant human erythropoietin for the treatment of resistant iron-deficiency anemia during pregnancy. Am J Obstet Gynecol 2001;184:662-7.

92 Breymann C, Richter C, Huttner C, et al. Effectiveness of recombinant erythropoietin and iron sucrose vs. iron therapy only, in patients with postpartum anaemia and blunted erythropoiesis. Eur J Clin Invest 2000;30:154-61

93 Krafft A, Breymann C, Huch R, et al. Intravenous iron sucrose in two pregnant women with inflammatory bowel disease and severe iron deficiency anemia. Acta Obstet Gynecol Scand 2000;79:720-2.

94 Weiss G, Meusburger E, Radacher G, et al. Effect of iron treatment on circulating cytokine levels in ESRD patients receiving recombinant human erythropoietin. Kidney Int 2003;64:572-8.

95 Kaltwasser JP, Kessler U, Gottschalk R, et al. Effect of recombinant human erythropoietin and intravenous iron on anemia and disease activity in rheumatoid arthritis. J Rheumatol $2001 ; 28: 2430-6$.

96 Oldenburg B, Berge Henegouwen GP, Rennick D, et al. Iron supplementation affects the production of pro-inflammatory cytokines in IL-10 deficient mice. Eur J Clin Invest 2000;30:505-10.

97 Emerit J, Pelletier S, Likforman J, et al. Phase II trial of copper zinc superoxide dismutase (CuZn SOD) in the treatment of Crohn's disease. Free Radic Res Commun 1991; 12-13(Pt 2):563-9.

98 Papadaki HA, Kritikos HD, Valatas V, et al. Anemia of chronic disease in rheumatoid arthritis is associated with increased apoptosis of bone marrow erythroid cells: improvement following anti-fumor necrosis factor-alpha antibody therapy. Blood 2002;100:474-82.

99 Pincus T, Olsen NJ, Russell IJ, et al. Multicenter study of recombinant human erythropoietin in correction of anemia in rheumatoid arthritis. Am J Med 1990;89:161-8

100 Glaspy J, Bukowski R, Steinberg D, et al. Impact of therapy with epoetin alfa on clinical outcomes in patients with nonmyeloid malignancies during cancer chemotherapy in community oncology practice. Procrit Study Group. J Clin Oncol 1997; 15:1218-34

101 Horina JH, Petritsch W, Schmid CR, et al. Treatment of anemia in inflammatory bowel disease with recombinant human erythropoietin: results in three patients. Gastroenterology 1993;104:1828-31.

102 Schreiber S, Howaldt S, Schnoor M, et al. Recombinant erythropoietin for the treatment of anemia in inflammatory bowel disease. N Engl J Med 1996:334:619-23.

103 Dohil R, Hassall E, Wadsworth LD, et al. Recombinant human erythropoietin for treatment of anemia of chronic disease in children with Crohn's disease. $J$ Pediatr 1998; 132:155-9.

104 Smith RE ir, Jaiyesimi IA, Meza LA, et al. Novel erythropoiesis stimulating protein (NESP) for the treatment of anaemia of chronic disease associated with cancer. Br J Cancer 2001;84(suppl 1):24-30.

105 Hodges P, Gee M, Grace M, et al. Vitamin and iron intake in patients with Crohn's disease. J Am Diet Assoc 1984;84:52-8.

106 Gee MI, Grace MG, Wensel RH, et al. Nutritional status of gastroenterology outpatients: comparison of inflammatory bowel disease with functional disorders. J Am Diet Assoc 1985;85:1591-9.

107 Imes S, Pinchbeck BR, Thomson AB. Diet counseling modifies nutrient intake of patients with Crohn's disease. J Am Diet Assoc 1987;87:457-62.

108 Geerling BJ, Badart-Smook A, Stockbrugger RW, et al. Comprehensive nutritional status in patients with long-standing Crohn disease currently in remission. Am J Clin Nutr 1998;67:919-26. 